\title{
Assessment of the level of implementation of metrological traceability requirements specific to measurement equipment in the laboratory for explosive materials and pyrotechnic articles
}

\author{
${\text { Cristian } \text { Cioara }^{1 *} \text {, Marius Morar }}^{1}$, Andrada Babut $^{1}$, and Ligia Tuhut $^{1}$ \\ ${ }^{1}$ National Institute for Research and Development in Mine Safety and Protection to Explosion - \\ INSEMEX Petrosani, Department of Safety of Explosion and Pyrotechnic Articles, G-ral V. Milea \\ Street 32-34, Petrosani, Romania
}

\begin{abstract}
The scientific article presents a synthesis on the analysis of the implementation of metrological traceability requirements specific to measuring equipment used for performing accredited tests in the field of explosives for civil use and pyrotechnic articles. In order to mitigate / minimize the risk related to the measurement uncertainty it is applied the proper traceability path in compliance with the requirements of the RENAR Policy, so that to ensure the availability of objective evidence for supporting metrological traceability, based on the documents of the implemented system. Also, the periodicity of calibration of measuring and testing equipment is between 2 and 6 years, being established according to the following criteria: level of use, regime of use, accuracy and stability requirements imposed in operation, metrological reliability performances of the equipment, quality of the working environment, the manufacturer's recommendations regarding the stability of the equipment. At the same time, the modification of this period is performed when there are significant changes of one or more parameters taken into account in the previous assessment, and in case of failure of a measuring equipment provided with a calibration certificate, it has to be calibrated again after its' repair.
\end{abstract}

\section{Introduction}

ILAC is the international authority for the accreditation of laboratories and inspection bodies, whose members are accreditation bodies and stakeholder organizations from around the world. [1]

ILAC provides the infrastructure to support the demonstration of worldwide competence and equivalence of testing (including medical) and calibration laboratories, inspection bodies and any other types of bodies that serve or support laboratories and inspection bodies during accreditation. Accreditation of laboratories and inspection bodies supports activities within $\mathrm{v}$ economies including trade, protection of health, safety and the environment for the benefit

\footnotetext{
* Cristian Cioara: cristian.cioara@insemex.ro
} 
of the public. Its main purpose is to give confidence to the competence of the bodies that support these activities. [1]

In this respect, the ILAC agreement is an international arrangement of multilateral mutual recognition for accreditation bodies. The participating accreditation bodies have agreed to promote the acceptance of the equivalence of the calibration, test and inspection reports issued by the accredited bodies. Before becoming a signatory to the ILAC Agreement, each accreditation body shall be subject to peer review in accordance with ILAC rules and procedures. [1]

To ensure confidence in the results of accredited laboratories, accreditation bodies implement ILAC policies and use guidance documents for a uniform and harmonized approach to accreditation criteria. Metrological traceability of measurement results is a key issue for which a harmonized policy is needed so that the market can trust the calibrations, tests and inspections performed by accredited laboratories and inspection bodies covered by the ILAC Arrangement. [1]

Metrological traceability requires an unbroken chain of calibrations to establish standards, all of which have established uncertainties. The persistent misconception that metrological traceability can be linked to a particular organization favors ongoing confusion about its nature (eg, "traceable to a National Institute of Metrology"). Metrological traceability refers to the quantitative reference values of the measurement standards and results, and not to the organization providing the results. [1]

Factors influencing the establishment of a harmonized ILAC policy on metrological traceability of measurement results include the following:

(a) The concept of metrological traceability of measurement results in areas such as chemistry, medical and biological sciences is still under development; [1]

(b) Not all economies have the full range of national standards or the best measurement and calibration capabilities needed to support the calibration and testing of all potential candidates' needs for accreditation in their economy; [1]

(c) The reliable and traceable role of certified reference materials in providing traceability of measurement results has not yet been fully established internationally.

\section{ILAC coding of traceability}

\subsection{Traceability covered by the ILAC commitment to calibrations}

The general requirement for traceability in SR EN ISO / IEC 17025: 2018 is:

The laboratory must establish and maintain the metrological traceability of its measurement results by means of an uninterrupted and documented chain of calibrations, each contributing to the measurement uncertainty, linking these results to an appropriate reference. $[1,3]$

It is an obligation of the laboratory to justify the need for calibration. In SR EN ISO/ IEC 17025: 2018 , the additional traceability requirement for calibration laboratories is:

The laboratory must ensure the traceability of the measurement results to the international SI system of units of measurement. [2]

For the reference standards the traceability requirements from SR EN ISO / IEC 17025: 2018 are:

The laboratory must have a program and procedure for the calibration of its reference standards. Reference standards must be calibrated by a body that can ensure traceability. Such reference standards of laboratory-held measurements should only be used for calibration and not for other purposes, unless it can be demonstrated that their performance as reference 
standards will not be invalidated. The reference standards must be calibrated before and after any adjustment. $[1,2]$

SR EN ISO / IEC 17025: 2018 also states that "When using external calibration services, the traceability of measurements must be ensured by using the calibration services of laboratories that can demonstrate competence, measurement capability and traceability." For reference equipment and standards to be calibrated, the ILAC policy states that they must be calibrated by:

1 A National Institute of Metrology whose service is adequate for the intended purpose and is covered by the CIPM MRA Arrangement. The services covered by the CIPM MRA are specified in Annex $\mathrm{C}$ of the BIPM KCDB, which includes the scope and measurement uncertainty for each listed service. $[1,3]$

2 An accredited calibration laboratory whose services are appropriate for the intended purpose (i.e., the purpose of the accreditation covers certain specific calibration) and the Accreditation Body is covered by the ILAC Arrangement (ILAC MRA) or ILACrecognized Regional Arrangements. [1, 3]

3a A National Institute of Metrology whose service is adequate for the intended purpose, but is not covered by the CIPM MRA. In these cases, the accreditation body must establish a policy to ensure that those services meet the relevant criteria for metrological traceability in SR EN ISO / IEC 17025: 2018. [1, 3]

$3 \mathrm{~b}$ A calibration laboratory whose service is adequate for the intended purpose but not covered by the ILAC Arrangement or ILAC-recognized Regional Arrangements. In this situation the accreditation body must establish a policy to ensure that those services meet the relevant criteria for metrological traceability in SR EN ISO / IEC 17025: 2018. $[1,3]$

Laboratories that have demonstrated the traceability of their measurements by using the calibration services provided in accordance with 1) or 2) above have used services that have been subject to relevant peer recognition or accreditation. Where $3 \mathrm{a}$ ) or $3 \mathrm{~b}$ ) apply, this is no longer the case, so these routes should only be applied if 1) or 2) are not possible for a specific calibration. The laboratory must therefore ensure that appropriate evidence is available for the declared traceability and measurement uncertainty, and that the accreditation body must assess this evidence.

SR EN ISO / IEC 17025: 2018, states: There are certain calibrations that cannot be done strictly in SI units. In such cases, calibration must ensure confidence in the measurements by establishing traceability to appropriate standards, such as:

- the use of certified reference materials provided by a competent supplier that give a credible physical or chemical characterization of a material;

- the use of specified methods and / or standards agreed by consensus which are clearly described and accepted by all parties involved.

Where possible, participation in an appropriate interlaboratory comparison program is required.

\subsection{Traceability covered by the ILAC commitment to testing}

The ILAC testing arrangement covers both test laboratories accredited according to SR EN ISO / IEC 17025: 2018 and medical laboratories accredited according to ISO 15189: 2007. In SR EN ISO / IEC 17025: 2018, the requirements for traceability in test laboratories are:

For test laboratories, the requirements apply to the measurement and test equipment with measurement functions used, unless it has been established that the uncertainty associated with the calibration contributes little to the total uncertainty of the test result. When this situation occurs, the laboratory must ensure that the equipment used can achieve the required measurement uncertainty. [2] 
In ISO 15189: 2007, the requirements are:

A program for calibration of the measurement and accuracy system must be designed and implemented to ensure that the results are traceable to SI units or by a reference, a natural constant or other indicated reference.

ILAC policy is:

If the calibration of the test equipment contributes significantly to the uncertainty, the same traceability policy applies (as detailed in points 1 to 4 above).

If the calibration does not significantly contribute to the test result, the laboratory must provide quantitative evidence demonstrating the low (insignificant) contribution associated with the calibration to the measurement result and the measurement uncertainty of the test and, consequently, traceability need not be demonstrated. [1,2]

In SR EN ISO / IEC 17025: 2018 the additional traceability requirement for test laboratories is:

Where traceability of measurements to SI units is not possible and / or is not relevant, the requirements for traceability to, for example, reference materials, accepted methods and / or consensus standards are the same as for calibration laboratories. [2]

In ISO / IEC 15189: 2007 the traceability requirement is:

Where none of these is possible or relevant, other methods must be applied to demonstrate confidence in the results, such as the following:

a) participation in an appropriate program of interlaboratory comparisons;

b) the use of appropriate reference materials, certified to characterize the material;

c) analysis or calibration according to another procedure;

d) comparison with reference values or equivalent values;

e) the use of standards or protocols of mutual recognition, clearly established, specified, characterized and unanimously recognized by all parties involved;

f) documentation with specifications regarding reagents, procedures or analysis system, when traceability is ensured by the supplier or manufacturer.

\subsection{Traceability provided by reference material (MRs) and certified reference material (MRCs)}

In relation to reference materials the traceability requirements of SR EN ISO / IEC 17025: 2018 include:

Reference materials should, where possible, be traceable to SI units of measurement or certified reference materials. [2]

The ILAC policy on traceability provided by PRMs is:

The values assigned to MRCs produced by a National Institute of Metrology and included in the KCDB database of BIPM, or produced by a PRM in the field of accreditation accredited according to ISO Guide 34: 2009 are considered to have established valid traceability.

The values assigned to the MRCs covered by the entries in the database of the Joint Committee for Traceability in Medical Laboratories (JCTLM) are considered to have established valid traceability.

Most MR and MRC are produced by other manufacturers. These can be considered as critical consumables and the laboratory must demonstrate that each MR or MRC corresponds to its intended use, as required by SR EN ISO / IEC 17025: 2018 or ISO 15189: 2007. [1-3]

\subsection{Recommendations for the situation where traceability is not established by the CIPM MRA and the ILAC arrangement}

Where traceability is set out in $3 \mathrm{a}$ ) or $3 \mathrm{~b}$ ) of the policy, action needs to be taken, primarily by the accreditation body that needs to address this situation in its traceability policy; 
secondly, from laboratories that need to comply with this policy; and finally, by the evaluators who will evaluate the effectiveness of this policy during the evaluations for the recognition of accreditation bodies between counterparts. It is recognized that the traceability covered by $3 \mathrm{a}$ ) and $3 \mathrm{~b}$ ) varies from calibrations performed by INMs outside the CIPM MRA, through accredited laboratories performing calibrations outside their accreditation area, to laboratories that are not accredited by any service (regardless of reason). [1]

Appropriate evidence of the technical competence of the laboratory and declared metrological traceability is likely to include, but is not limited to, the following: (numbers refer to the requirements of SR EN ISO / IEC 17025: 2018:

- Records for validation of the calibration method;

- Procedures for estimating uncertainty;

- Documenting the traceability of measurements;

- Documenting how the quality of calibration results is ensured;

- Documentation of staff competence;

- Documentation of accommodation and environmental conditions;

- Calibration laboratory audits.

\section{Determination of calibration intervals of measuring devices}

\subsection{General aspects regarding the configuration of the calibration system}

An important aspect of maintaining a laboratory's ability to provide traceable and reliable measurement results is to determine the maximum period that should be allowed between successive calibrations (recalibrations) of the reference standards or working standards and measuring devices used. [4]

The general purpose of a periodic calibration is:

- improve the estimation of the deviation between a reference value and a value obtained using a measuring instrument, and the uncertainty of this deviation at the time the device is used;

- to reassure the uncertainty that can be obtained with the measuring device;

- to confirm whether or not there has been an alteration of the measuring device which could lead to doubts regarding the results obtained in the past period.

One of the most significant calibration decisions is "When to do it" and "How often to do it." A large number of factors influence the time interval that should be allowed between calibrations and that should be taken into account by the laboratory. The most important factors are:

- the measurement uncertainty required or declared by the laboratory;

- the risk of a measuring instrument exceeding the maximum permissible error limit when in use;

- the costs of corrective measurements required to be performed when it is found that the measuring instrument has not been adequate for a long time;

- type of device;

- tendency to wear and drift;

- manufacturer's recommendation;

- the extent and severity of use;

- environmental conditions (climatic conditions, vibrations, ionizing radiation, etc.);

- trends of the measuring device obtained from the records from previous calibrations;

- recorded history of maintenance and repair works;

- frequency of cross-checks with other reference standards or measuring devices;

- frequency and quality of intermediate checks over time; 
- transport conditions and risks;

- the degree to which service personnel are trained.

Although the cost of a calibration cannot normally be ignored in determining calibration intervals, increased measurement uncertainties or a higher risk in ensuring the quality of measurement results and services caused by long intervals may decrease the apparently high cost of a calibration. [4]

The process of determining calibration intervals is a complex mathematical and statistical process that requires accurate and sufficient data collected during the calibration process. Apparently, there is no best practical way that can be universally applied for setting and adjusting calibration intervals. This has created a need for a better understanding of the calibration interval determination. [4]

\subsection{Initial choice of calibration intervals}

The initial decision in determining the calibration interval is based on the following factors:

- recommendations of the measuring device manufacturer;

- expectations regarding the extent and severity of use;

- the influence of the environment;

- the required measurement uncertainty;

- maximum permissible errors (e.g., by legal metrology authorities);

- adjustments (or modifications) of the measuring device;

- the influence of the measured quantity (e.g., the effect of high temperature on the thermocouples);

- information published or in common databases about the same or similar measuring devices.

The decision should be made by a person or persons with general experience in the field of measurements, or specific measuring devices to be calibrated, and preferably with knowledge of the calibration intervals applied by other laboratories. An estimate should be made for each measuring instrument or group of measuring instruments over a period of time during which the measuring instrument is likely to remain below the maximum permissible error after calibration. [4]

\subsection{Revision of the calibration interval}

Once the calibration interval has been established on the basis of a routine algorithm, an adjustment of the calibration intervals could be possible in order to optimize the balance between risks and costs, as mentioned in the introduction.

It will probably be found that the initially chosen calibration intervals do not give the desired optimal results due to some causes, for example:

- measuring devices may be less reliable than expected;

- the use regime may not be the anticipated one;

- a limited calibration of certain measuring instruments may be sufficient instead of a complete calibration;

- the sliding tendency caused by the recalibration of the measuring devices may show that longer calibration intervals may be possible without increasing the risks, etc.

A number of methods are available for reviewing calibration intervals. The chosen method differs if:

- measuring devices are treated individually or in groups (e.g., according to the manufacturer's model or type);

- measuring devices exceed the calibration by trends manifested in time or by use;

- measuring devices show different types of instabilities; 
- measuring devices undergo adjustments;

- data are available, with their significance, regarding the calibration history of the measuring devices.

The so-called "engineering intuition" that established the initial calibration intervals, and a system that maintains fixed intervals without revisions, are not considered reliable and are therefore not recommended. [4]

\section{Implementation of traceability requirements at the level of measuring equipment within the Laboratory for Explosive Materials and Pyrotechnic Articles}

At the level of the Testing Laboratories Group (GLI) within INCD INSEMEX Petrosani, the demonstration of the traceability of the measurements performed within these laboratories (of which LMEAP is part of) is performed based on the system procedure "PS-08 Traceability of the measurement". [5]

According to this procedure, the main rules established to ensure traceability, take into account the following:

The traceability of the measurement, provides objective evidence to ensure the reporting to international or national standards of the measurements made and the reference materials used by the laboratory.

All equipment used for testing, including equipment for subsidiary measurements (for environmental conditions), which has a significant effect on the accuracy or validity of test results shall be calibrated before being put into service.

INSEMEX-GLI requests the calibration and the obtaining of calibration certificates for test equipment from entities that can ensure traceability under the RENAR P-05 policy, [3] such as:

- A National Institute of Metrology whose services are adequate and covered by the CIPM MRA arrangement and are indicated by the inclusion of the CIPM-MRA logo;

- An accredited calibration laboratory whose services are adequate and the Accreditation Body is a signatory to the ILAC Arrangement (ILAC MRA). These services are indicated by the inclusion of the national accredited mark on the calibration certificates;

- A National Institute of Metrology whose services are adequate but not covered by the CIPM MRA arrangement;

- An accredited calibration laboratory whose services are adequate but not covered by the ILAC arrangement (ILAC MRA).

The periodicity of equipment calibration is $2 \div 6$ years. This period was established according to the following criteria:

- degree of use;

- mode of use;

- the accuracy and stability requirements imposed in use;

- metrological reliability performance of the equipment;

- quality of the working environment;

- the manufacturer's stability recommendations.

The change of this period is made when there are significant changes of one or more parameters taken into account in the previous evaluation. If equipment with a calibration certificate has failed, it will be recalibrated after repair. [5]

Calibration certificates are archived and kept throughout the life of the equipment in such a way that the history of the metrological confirmation status for each piece of equipment and its traceability to national and international standards can be reconstructed. [5] 
In order to ensure the maintenance of the equipment used in the tests, it is regularly checked that it is in good working order by comparison with standard reference equipment or reference material. The results of these measurements shall be recorded in the primary records or in the Internal Audit Reports. [5]

The internal verification report ensures the traceability of the measurement with equipment used at national and international standards.

\section{Examples of ensuring the traceability of measurement for Laboratory for Explosive Materials and Pyrotechnic Articles}

At the level of the Laboratory for Explosive Materials and Pyrotechnic Articles - LMEAP, accredited by RENAR, an annual "Plan for calibration of test equipment" is drawn up and endorsed, in which each piece of equipment is documented, identified by its generic name, series, field measurement and accuracy, the date of the existing calibration certificate and the date of the next calibration.

In the endowment of the laboratory there are currently a number of 25 equipment of which we can exemplify for each traceability route the following equipment:

For Calibration Route 1, the calibration certificate no. 01.03-308 / 2018 dated 19.09.2018 of the Integrating Sound Level Meter type 2250 Light, issued by INM Bucharest, certificate corresponding to the requirements of traceability route 1 of the P-05 RENAR policy, having the CIMP MRA logo printed on its surface.

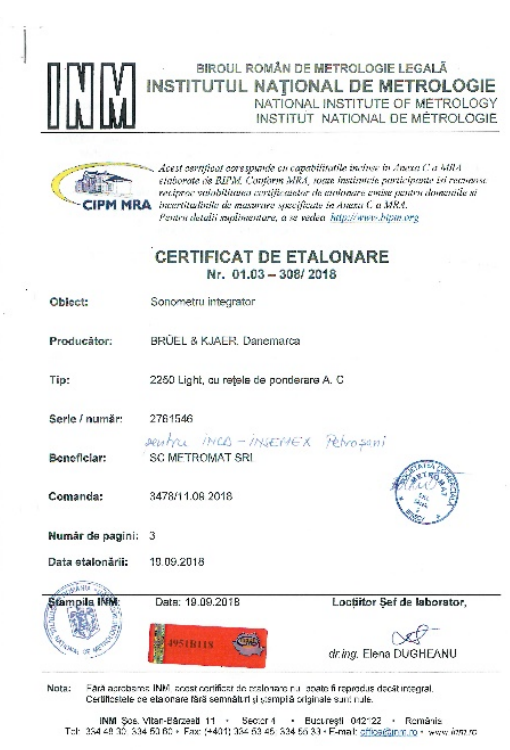

Fig. 1. Calibration certificate on the traceability route 1 .

For Calibration Route 2, the calibration certificate no. 15503-11.20 dated 10.11.2020 of the Measuring Roulette, issued by S.C. METROMAT S.R.L. Brasov, certificate that corresponds to the requirements of traceability route 2 of the P-05 RENAR policy, having the RENAR accreditation logo and the ILAC arrangement logo (ILAC MRA) printed on its surface. 


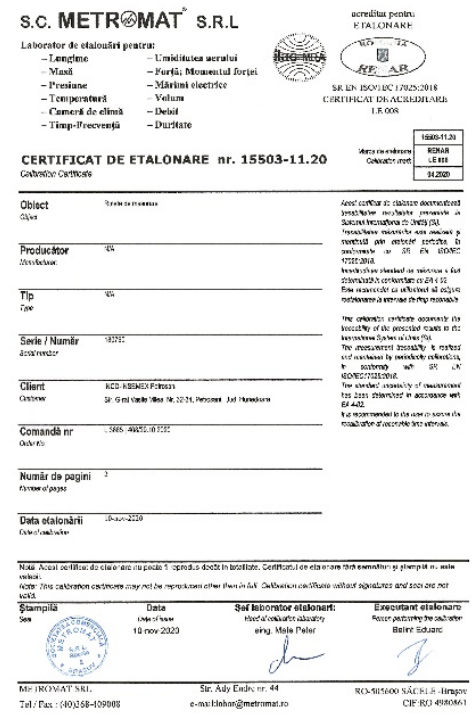

Fig. 2. Calibration certificate on the traceability route 2 .

For Calibration Route 3a, the calibration certificate no. 05.03-566 / 2019 dated 22.05.2019 of the Stationary gas analyzer type laboratory interferometer for binary mixtures, issued by INM Bucharest, certificate corresponding to the requirements of traceability route $3 \mathrm{a}$ of the P-05 RENAR policy, is not covered by the arrangement CIPM MRA and does not have the CIMP MRA logo printed on its surface.

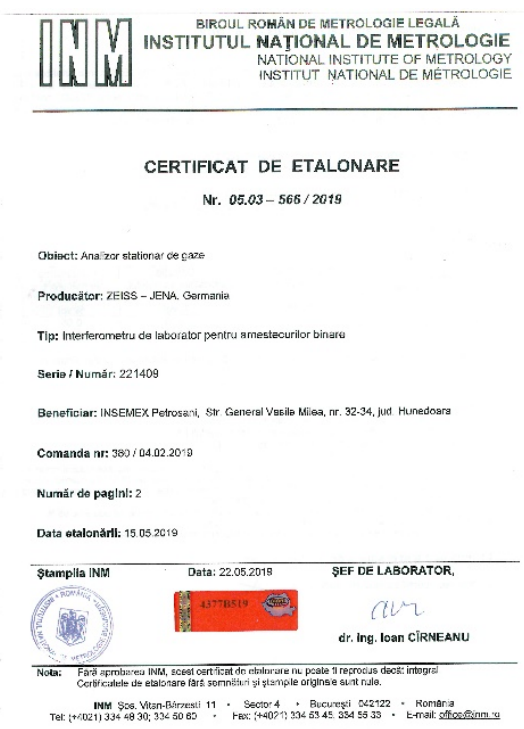

Fig. 3. Calibration certificate on the traceability route $3 \mathrm{a}$.

For Calibration Route 3b, the calibration certificate no. MG-08-20-008 dated 27.08 .2020 of the set of special weights with nominal values of $0.5 \mathrm{~kg}, 1 \mathrm{~kg}, 2 \mathrm{~kg}, 5 \mathrm{~kg}$ and $10 \mathrm{~kg}$, issued by S.C. METROMAT S.R.L. Brasov, a certificate that meets the requirements of traceability route $3 \mathrm{~b}$ of the P-05 RENAR policy, is not covered by the ILAC arrangement (ILAC MRA). 


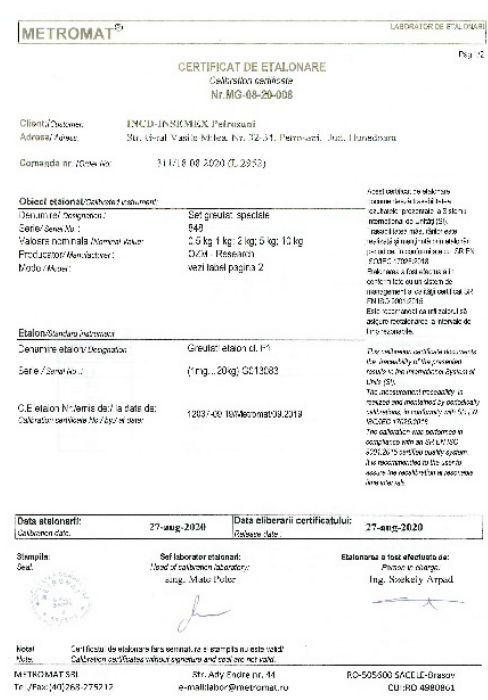

Fig. 4. Calibration certificate on the traceability route $3 b$.

\section{Conclusions}

The topic addressed in this scientific article was focused on the results of the study to analyze the implementation of metrological traceability requirements on measuring equipment used in RENAR accredited tests in the field of explosives for civil use and pyrotechnic articles.

International cooperation for the accreditation of laboratories is the authority in the field that provides the methodological infrastructure and requirements policy needed to demonstrate competencies in the field of metrological traceability and equivalence of calibration laboratories around the world.

The technical and methodological aspects related to the calibration and obtaining of calibration certificates for the test equipment used in tests by recognized and competent entities that can ensure traceability according to the P-05 RENAR policy have been documented.

The examples presented in the paper, highlight the particularization of the generalized traceability scheme for each route, summarizing the particular form of the type of document issued for each case depending on the type of service covered by the inclusion of the logo and / or national accreditation mark.

\section{References}

1. Politica ILAC de trasabilitate a rezultatelor măsurării, (2013)

2. Standard SR EN ISO/ IEC 17025:2018

3. RENAR P-05, Politica privind trasabilitatea metrologică a rezultatelor măsurărilor, (2019)

4. Linii directoare pentru determinarea intervalelor de etalonare a aparatelor de măsurare (2007)

5. Procedură de system PS-08, Trasabilitatea măsurării, (2019) 